\title{
Water as the primary beverage: A predictor of pediatric obesity
}

\author{
Kelly Meier ${ }^{1}$, Cindy Minton ${ }^{2}$, Bethany Meyer ${ }^{3}$, Son Chae Kim ${ }^{* 4}$ \\ ${ }^{1}$ Taylor Primary Care, United States \\ ${ }^{2}$ Matrix Medical Network, United States \\ ${ }^{3}$ West Texas Medical Care, United States \\ ${ }^{4}$ St. David's School of Nursing, Texas State University, United States
}

Received: March 19, 2016

DOI: $10.5430 /$ jnep.v6n10p65
Accepted: May 15, 2016

Online Published: May 26, 2016

URL: http://dx.doi.org/10.5430/jnep.v6n10p65

\begin{abstract}
Aims: The aims of this study were to assess parental awareness of their own children's weight status and healthy habits, as well as to determine whether the daily use of water as a child's primary beverage is a predictor of pediatric obesity or overweight. Methods: A cross-sectional study was conducted at two primary pediatric clinics and one urgent care clinic from September 2014 to November 2014. Data were collected from children's medical records as well as from parents of children aged 2-18 years. Chi-square tests, bivariate correlations, and multivariate logistic regression procedures were performed.

Results: Two-thirds of parents with obese or overweight children were not aware of their children's weight status. Male gender emerged as the positive predictor of pediatric obesity or overweight (Odds Ratio [OR], 9.86; 95\% Confidence Interval [CI], $1.21-80.4 ; p=.033$ ), whereas using water as the primary beverage throughout the day, with low-fat/skim milk at mealtimes was a negative predictor (OR, 0.019; $95 \% \mathrm{CI}, 0.001-0.24 ; p=.002$ ).

Conclusions: There were nearly 50 -fold lower odds of being obese or overweight for children who use water as the primary beverage throughout the day than those who do not. Rather than focusing on negative impacts of sugar-sweetened beverages or $100 \%$ fruit juice, more attention should be paid to the positive impact of using water as the primary beverage throughout the day. Using standardized Body Mass Index (BMI) percentile growth charts, children's weight status should be communicated to all parents. Teaching and motivating parents and children to drink water as their primary beverage throughout the day could be an effective approach to preventing and managing pediatric obesity.
\end{abstract}

Key Words: Pediatric obesity, Obesity risks, Predictors, Beverages, Parental questionnaire

\section{INTRODUCTION}

The epidemic of pediatric obesity has recently become a major public health problem in the United States, with about one-third of the pediatric population being overweight or obese. $^{[1]}$ Pediatric obesity can lead to numerous negative health consequences, including developmental and mental health problems, otitis media, sleep apnea, and type 2 diabetes mellitus, and frequently continues into adulthood. ${ }^{[2,3]}$
It is estimated that about $40 \%$ of American adults will be obese by 2030 , and if the prevalence of obesity were to be held at $15 \%$ for two decades, the potential medical cost savings could be as much as $\$ 1.9$ trillion. ${ }^{[4]}$

According to the Centers for Disease Control and Prevention (CDC) growth chart, pediatric overweight is defined as a body mass index (BMI) between the 85th and less than the 95th percentiles, and obesity is defined as the 95th per-

*Correspondence: Son Chae Kim; Email: sck30@txstate.edu; Address: 1555 University Blvd. Round Rock, TX, 78665, USA. 
centile or greater. ${ }^{[5]}$ Although guidelines are available for the prevention and management of pediatric obesity in primary care settings, many providers are unaware of these guidelines or do not follow them, including the recommendation to document BMI percentiles. ${ }^{[6,7]}$ The guidelines also recommend parental involvement in management of obesity, but a meta-analysis of 69 studies showed that only half of the parents with overweight/obese children were aware of their children's weight status. ${ }^{[8]}$ In addition, less than a quarter of parents were apparently told by their healthcare providers that their children were overweight. ${ }^{[9]}$

Parental awareness and involvement are critical in preventing and managing pediatric obesity. A growing body of evidence indicates that family-centered interventions targeting both children and parents are effective in improving parents' self-efficacy, as well as their children's obesity. ${ }^{[10,11]}$ Furthermore, parents' concerns about their children's weight status and their involvement in addressing those concerns have positive relationships with improving the children's physical activity and diet, as well as decreasing consumption of sugar-sweetened beverages (SSBs). ${ }^{[12,13]}$

Regular consumption of SSBs was associated with weight gain among children, according to a meta-analysis of 32 prospective cohort and randomized controlled studies. ${ }^{[14]}$ Another study showed that Hispanic and African American children consumed more total SSBs compared with whites. ${ }^{[15]}$ This negative impact of SSB consumption on pediatric obesity has led to a concerted effort to reduce SSB consumption in public schools. However, banning the sale of soda only resulted in students shifting to other SSBs, such as sports drinks, energy drinks, or fruit drinks. ${ }^{[16]}$ In spite of the tremendous attention paid to the association between pediatric obesity and the consumption of various beverages, less attention has been paid to the positive impact of using water as the primary beverage throughout the day. ${ }^{[17]}$ Consequently, there is a dearth of research examining the strength of the association between the use of water as the primary beverage throughout the day and weight status in children.

\section{Study aims}

The aims of this study were to assess parental awareness of their own children's weight status and healthy habits, as well as to determine whether the daily use of water as a child's primary beverage is a predictor of pediatric obesity or overweight.

\section{Methods}

\subsection{Design and setting}

A descriptive, cross-sectional design was used in the current study. Parents of children aged 2-18 years were recruited from two primary pediatric clinics and one urgent care clinic from September to November of 2014. The study was reviewed and approved by the university institutional review board. Parents who agreed to participate in the study were interviewed to collect the data.

\subsection{Data collection tools}

A standardized data collection tool was used to obtain children's age, gender, ethnicity, weight, and height from the medical records. Family histories of type 2 diabetes mellitus, hypertension, hyperlipidemia, obesity, and early death from heart disorder or stroke were also collected from the medical records. Children's BMI and BMI percentile were calculated based on weight, height, age, and gender, using the BMI calculator from the CDC. A code number was assigned to each child and parent to allow matching of the child's medical record data with the information from the parent.

A 10-item questionnaire assessing children's healthy habits was chosen to collect information from parents. ${ }^{[18]}$ Questionnaire items included daily screen time (e.g., TV, video, or computer games); daily servings of vegetables and fruits; daily physical activity; water as the primary beverage throughout the day, with low-fat/skim milk at mealtimes; use of food to reward positive behavior; consumption of high-fat foods; outdoor activity; family physical activity; and parents' perception of their own weight. In the current study, content validity testing was performed among a panel of nine experts for clarity and relevance of each question item on a four-point, Likert-type response. The content validity indices (CVI) were all above 70\%, except for one item regarding high-fat foods, which was revised by adding the phrase "such as potato chips, donuts, or ice cream." One item, "Compared to other children of the same age, do you feel your child is: underweight, average weight, overweight or obese?" was added to obtain parental awareness of their children's weight status. ${ }^{[19]}$ The revised tool, containing these 11 items, was named the Pediatric Healthy Habits Assessment Tool (PHHAT).

\subsection{Data analysis}

Descriptive statistics included frequencies and percentages of children's demographics, weight status categories, parental awareness of their children's weight status, and pediatric healthy habits. In the current study, BMI $\geq 85$ th percentile was used to define pediatric obesity and/or overweight. Each child's weight status was recoded into a dichotomous variable, BMI $<85$ th percentile $v s$. BMI $\geq 85$ th percentile. The children's demographic variables and healthy habits were also recoded as dichotomous variables, and Chi-square tests with Fisher's exact tests were performed to compare the BMI 
$<85$ th and BMI $\geq 85$ th percentile groups.

Bivariate correlations procedures using Kendall's tau test were performed among dichotomous variables to identify the statistically significant relationships among demographic variables, healthy habits, and BMI $\geq 85$ th percentile. Demographic variables and healthy habits were entered into the multivariate logistic regression model to explore the predictors of BMI $\geq 85$ th percentile. The level of significance was set at $p$ value $<.05$, and SPSS software version 21.0 (IBM, Chicago, IL, USA) was utilized for all data analyses.

\section{RESULTS}

\subsection{Characteristics of children}

A total of 47 parents participated in the study. The mean age of the children was 9.6 years, with the majority being male $(51.1 \%)$ and of Hispanic ethnicity (63.8\%). Twenty-four children $(51 \%)$ had BMI $\geq 85$ th percentile and of whom, 16 had $\mathrm{BMI} \geq 95$ th percentile. More than one-third of the children had positive family histories of hypertension (48.9\%), type 2 diabetes mellitus (42.6\%), or hyperlipidemia (38.3\%). Table 1 presents the sample characteristics.

Table 1. Sample characteristics $(\mathrm{N}=47)$

\begin{tabular}{|c|c|c|c|}
\hline & $\begin{array}{l}\mathrm{BMI}<85^{\text {th }} \\
\text { percentile } \\
(n=23) \\
n(\%)\end{array}$ & $\begin{array}{l}\mathrm{BMI} \geq 85^{\text {th }} \\
\text { percentile } \\
(n=24) \\
n(\%)\end{array}$ & $\begin{array}{l}\text { Total } \\
(N=47) \\
n(\%)\end{array}$ \\
\hline \multicolumn{4}{|l|}{ Age categories } \\
\hline $2-5$ years & $9(39.1)$ & $2(8.3)$ & $11(23.4)$ \\
\hline $6-11$ years & $7(30.4)$ & $13(54.2)$ & $20(42.6)$ \\
\hline $12-18$ years & $7(30.4)$ & $9(37.5)$ & $16(34.0)$ \\
\hline Age, mean (range), years & $8.5(2-17)$ & $10.6(3-17)$ & $9.6(2-17)$ \\
\hline \multicolumn{4}{|l|}{ Gender } \\
\hline Male & $9(39.1)$ & $15(62.5)$ & $24(51.1)$ \\
\hline Female & $14(60.9)$ & $9(37.5)$ & $23(48.9)$ \\
\hline \multicolumn{4}{|l|}{ Ethnicity } \\
\hline Non-Hispanic white & $6(26.1)$ & $5(20.8)$ & $11(23.4)$ \\
\hline African American & $4(17.4)$ & $2(8.3)$ & $6(12.8)$ \\
\hline Hispanic & $13(56.5)$ & $17(70.8)$ & $30(63.8)$ \\
\hline \multicolumn{4}{|l|}{ Weight (BMI percentiles) } \\
\hline Underweight $\left(<5^{\text {th }}\right)$ & $4(17.4)$ & N/A & $4(8.5)$ \\
\hline Healthy weight $\left(5^{\text {th }}\right.$ to $\left.84^{\text {th }}\right)$ & $19(82.6)$ & N/A & $19(40.4)$ \\
\hline Overweight $\left(\geq 85^{\text {th }}\right.$ to $\left.94^{\text {th }}\right)$ & N/A & $8(33.3)$ & $8(17.0)$ \\
\hline Obese $\left(\geq 95^{\text {th }}\right)$ & N/A & $16(66.7)$ & $16(34.0)$ \\
\hline \multicolumn{4}{|l|}{ Family history } \\
\hline Type 2 diabetes mellitus & $7(30.4)$ & $13(54.2)$ & $20(42.6)$ \\
\hline Hypertension & $8(34.8)$ & $15(62.5)$ & 23 (48.9) \\
\hline Hyperlipidemia & $7(30.4)$ & $11(45.8)$ & $18(38.3)$ \\
\hline Obesity & $1(4.3)$ & $4(16.7)$ & $5(10.6)$ \\
\hline $\begin{array}{l}\text { Early death from heart } \\
\text { disorder/stroke }\end{array}$ & $3(13.0)$ & $7(29.2)$ & $10(21.3)$ \\
\hline
\end{tabular}

Note: $\mathrm{BMI}=$ body mass index; $\mathrm{N} / \mathrm{A}=$ not applicable.

Percentages may not add up to $100 \%$ because of missing data or rounding.

\subsection{Parents' awareness of children's weight status and healthy habits}

Among the parents of 24 children with BMI $\geq 85$ th percentile, sixteen parents $(67 \%)$ were not aware of their children's weight status. Figure 1 shows the comparison of healthy habits among children with BMI $<85$ th percentile versus $\mathrm{BMI} \geq 85$ th percentile. There were statistically significant differences between the two groups in daily physical activity $>60$ minutes $(65.2 \%$ vs. $29.2 \%$ for the BMI $<85$ th percentile group $v s$. the $\mathrm{BMI} \geq 85$ th percentile group; $p=$ .020 ) and water as the primary beverage throughout the day, with low-fat/skim milk at mealtimes $(78.3 \%$ vs. $29.2 \%$; $p=$ $.001)$. However, no statistically significant differences were found between the two groups with regards to the use of food to reward positive behavior, regular family physical activity, and daily screen time less than 2 hours.

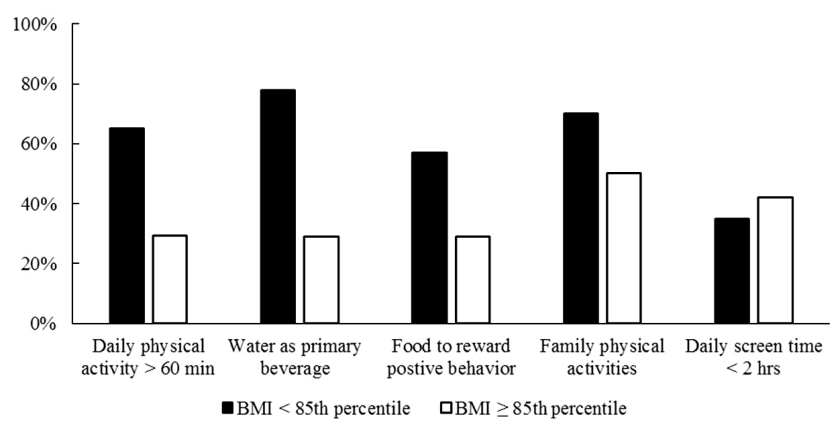

Figure 1. Pediatric healthy habits in $\mathrm{BMI}<85$ th $v s . \mathrm{BMI} \geq$ 85 th percentile groups $(\mathrm{N}=47)$

\subsection{Daily use of water as a predictor of pediatric obesity or overweight}

Bivariate correlations by Kendall's tau test revealed that daily physical activity $>60$ minutes $(r=-0.36 ; p=.014)$ and water as the primary beverage throughout the day, with lowfat/skim milk at mealtimes $(r=-0.49 ; p=.001)$ had significantly negative relationships with $\mathrm{BMI} \geq 85$ th percentile (see Table 2). To identify the predictors of BMI $\geq 85$ th percentile, the demographic variables and pediatric healthy habits were entered into a multivariate logistic regression model. Male gender emerged as the only significant positive predictor (Odds Ratio $[\mathrm{OR}]>1.0$ ) of $\mathrm{BMI} \geq 85$ th percentile $(\mathrm{OR}$, 9.86; 95\% Confidence Interval [CI], 1.21-80.4; $p=.033$ ), whereas using water as the primary beverage throughout the day, with low-fat/skim milk at mealtimes (OR, 0.019; 95\% CI, 0.001-0.24; $p=.002)$, and use of food to reward positive behavior (OR, 0.06; 95\% CI, 0.006-0.67; $p=.021$ ) were negative predictors $(\mathrm{OR}<1.0)$ of $\mathrm{BMI} \geq 85$ th percentile (see Table 3). 
Table 2. Bivariate correlations with $\mathrm{BMI} \geq 85$ th percentile $(\mathrm{N}=47)$

\begin{tabular}{lll}
\hline & $\begin{array}{c}\text { Correlation } \\
\text { coefficients }\end{array}$ & $\boldsymbol{p}$ \\
\hline Gender, male & 0.23 & .113 \\
Family history of type 2 diabetes mellitus & 0.24 & .104 \\
Family history of obesity & 0.20 & .176 \\
Family history of hypertension & 0.28 & .060 \\
Daily physical activity $>$ 60 minutes & -0.36 & $.014^{*}$ \\
Water as the primary beverage throughout the & -0.49 & $.001^{* *}$ \\
day, low-fat/skim milk at mealtimes & -0.28 & .061 \\
Use of food to reward positive behavior & -0.21 & .164 \\
At least one parent maintains a healthy weight & &
\end{tabular}

Note: ${ }^{*} p<.05 ;{ }^{* *} p<.01$ by Kendall's tau; only variables with $p$ value $<.20$ are shown.

Table 3. Multivariate logistic regression in predicting BMI $\geq 85$ th percentile $(\mathrm{N}=47)$

\begin{tabular}{|c|c|c|c|}
\hline & OR & $95 \% \mathrm{CI}$ & $p$ \\
\hline Gender, male & 9.86 & $1.21-80.4$ & $.033^{*}$ \\
\hline Hispanic ethnicity & 5.57 & $0.76-40.8$ & .091 \\
\hline $\begin{array}{l}\text { Family history of type } 2 \text { diabetes } \\
\text { mellitus }\end{array}$ & 5.56 & $0.79-39.4$ & .086 \\
\hline $\begin{array}{l}\text { Water as the primary beverage } \\
\text { throughout the day, low-fat/skim milk } \\
\text { at mealtimes }\end{array}$ & 0.019 & $0.001-0.24$ & $.002^{* *}$ \\
\hline $\begin{array}{l}\text { Use of food to reward positive } \\
\text { behavior }\end{array}$ & 0.06 & $0.006-0.67$ & $.021^{*}$ \\
\hline
\end{tabular}

Note: ${ }^{*} p<.05 ; * * p<.01$. OR = Odds Ratio; $\mathrm{CI}=$ confidence interval.

\section{Discussion}

There were nearly 50 -fold lower odds of being obese or overweight for children who use water as the primary beverage throughout the day, with low-fat or skim milk at mealtimes, than those who do not. This result from the current study is largely consistent with findings from a randomized controlled study that drinking water or non-caloric beverages in place of sugar-sweetened beverages (SSBs) significantly reduced weight gain by an average of $1.01 \mathrm{~kg}$ (or $2.2 \mathrm{lb}$ ) over 18 months in children. ${ }^{[20]}$ Although the study was conducted in subjects with healthy body weight and did not examine the rate of obesity, the reduction in weight gain associated with water points to the importance of beverage choice in controlling the pediatric obesity epidemic.

Tremendous attention has been paid in the past to the impact of SSB consumption on pediatric obesity, as well as to reducing consumption of various SSBs, such as carbonated soda, fruit drinks, and energy/sports drinks. Even consumption of $100 \%$ fruit juice, which was promoted as being equivalent to the recommended consumption of whole fruit, now appears to be associated with pediatric obesity. ${ }^{[21]}$ Rather than focusing on negative impacts of caloric beverages, perhaps more attention should be paid to the positive impact of using water as the primary beverage throughout the day, with low-fat/skim milk at mealtimes. Promoting water and providing low-cost, easily accessible, good-tasting water at schools, homes, and day care centers could foster the use of water as the primary beverage throughout the day and help reduce pediatric obesity and overweight.

The current study also suggests that boys had almost a 10fold higher odds of being obese or overweight than girls. Similarly, a previous study reported that boys were more likely to be obese or overweight than girls. ${ }^{[22]}$ In addition, boys were more likely than girls to have their weight underestimated by their parents. ${ }^{[23]}$ Gender differences in obesity, as well as differences in parental perceptions of girls and boys, may be due to differences in body fat distribution, cultural gender bias regarding obesity, physical activity, and diet. ${ }^{[23,24]}$

An unexpected finding of the current study was that the use of food to reward positive behavior was a negative predictor $(\mathrm{OR}<1)$ of obesity or overweight in the multivariate analysis. In contrast, a previous study reported a positive association between using food as a reward and weight gain. ${ }^{[25]}$ Although information regarding the types of food used as rewards was not collected, it may be possible that the use of low-calorie food to reward good behavior may have helped to protect children from obesity. In addition, no effects resulting from screen time, daily servings of fruits and vegetables, high-fat snacks, or physical activity were found, in contrast to previous studies. ${ }^{[2,27]}$ This may have been due to the small sample size in the current study, which limited the possibility of detecting small effect sizes.

Approximately half of the children in the current study were obese or overweight, but two-thirds of the parents were apparently not aware of their children's weight status, or they had inaccurate perceptions of their children's weight. This result is consistent with previous studies, which showed that approximately one-third to one-half of parents underestimated their own children's weight status. ${ }^{[8,23]}$

Obesity is a complex health problem that needs to be treated as a chronic disease and managed with a chronic care model. ${ }^{[7,28]}$ For nurses involved in care of pediatric population, it is essential to perform universal documentation of BMI percentiles at regular intervals to identify children at risk for obesity. ${ }^{[7,29]}$ Using the gender- and age-specific BMI percentile growth charts, nurses should communicate the results with parents regarding their children's weight status. For obese or overweight children, the focus of the conversation should not be on weight loss or dieting, but rather should be on a healthy lifestyle through encouragement to grow into weight. ${ }^{[9]}$ 
Parents' awareness of their children's weight status is the first step toward parental involvement in maintaining healthy weight and influencing their children's choice of beverages, as well as fostering healthy habits. ${ }^{[12]}$ Teaching and motivating parents and children to drink water as their primary beverage throughout the day, with skim/low-fat milk at mealtimes, could be an effective approach to preventing and managing pediatric obesity. This may be especially effective in those families that consume large amounts of sugar-sweetened beverages or $100 \%$ fruit juice. A family-centered approach would target both parents and children concurrently; incorporate cultural, ethnic, and socioeconomic backgrounds; and utilize multidisciplinary resources of nutritionists, counselors, or physical therapists available in the community. ${ }^{[7,11]}$

\section{Limitations}

The current study had several limitations. First, the study findings of predictors of male gender, water use as the primary beverage, and use of food as a reward should not be taken as cause-and-effect relationships for pediatric obesity or overweight in this cross-sectional study. Second, although the effect sizes represented by the odds ratios were large and statistically significant, the $95 \%$ confidence intervals were large due to the small sample size. Third, the study findings may not be generalizable, since the study was conducted in central Texas with a sample containing a high proportion of Hispanics. Fourth, a convenience sampling method used in the current study may have introduced selection bias. Finally, the self-reported data may have over- or underestimated parental responses. Further studies, with larger sample sizes, are needed to confirm the impact on pediatric obesity and overweight of using water as the primary beverage.

\section{Conclusions}

This study indicates that the use of water as the primary beverage throughout the day, with low-fat or skim milk at mealtimes, is a strong negative predictor of pediatric obesity with nearly 50 -fold lower odds of being obese or overweight. There is an intriguing possibility that simply changing the primary beverage to water for those children who consume sugar-sweetened beverages or $100 \%$ fruit juice can reduce pediatric obesity. In addition, there appears to be room for improvement in parents' awareness of their own children's weight status. Nurses involved in care of pediatric population can play a major role in screening, educating, and motivating parents, and implementing the practice guidelines to prevent and manage pediatric obesity. If the use of water as the primary beverage throughout the day is confirmed to be an important negative predictor of obesity, focusing on the positive impact of water may facilitate the prevention and management of pediatric obesity.

\section{CONFLiCTS OF INTEREST Disclosure}

The authors declare that there are no conflicts of interest.

\section{REFERENCES}

[1] Ogden CL, Carroll MD, Kit BK, et al. Prevalence of childhood and adult obesity in the United States, 2011-2012. JAMA. 2014; 311(8): 806-814. PMid:24570244. http://dx.doi.org/10.1001/jama. 2014.732

[2] Halfon N, Larson K, Slusser W. Associations between obesity and comorbid mental health, developmental, and physical health conditions in a nationally representative sample of US children aged 10 to 17. Academic Pediatrics. 2013; 13(1): 6-13. PMid:23200634. http://dx.doi.org/10.1016/j.acap. 2012.10.007

[3] D'Adamo E, Caprio S. Type 2 diabetes in youth: Epidemiology and pathophysiology. Diabetes Care. 2011; 34 Suppl 2: S161-165. PMid:21525449. http://dx.doi.org/10.2337/dc11-s212

[4] Finkelstein EA, Khavjou OA, Thompson H, et al. Obesity and severe obesity forecasts through 2030. American Journal of Preventive Medicine. 2012; 42(6): 563-570. PMid:22608371. http: //dx.doi.org/10.1016/j.amepre.2011.10.026

[5] Centers for Disease Control and Prevention (CDC): Defining Childhood Obesity. Available from: http://www.cdc.gov/obesity/ childhood/defining.html

[6] Tanda R, Salsberry P. The impact of the 2007 expert committee recommendations on childhood obesity preventive care in primary care settings in the United States. Journal of Pediatric Health Care. 2014; 28(3): 241-250. PMid:23831376. http://dx.doi.org/10.1016 /j.pedhc. 2013.05.009

Published by Sciedu Press
[7] Daniels SR, Hassink SG, Committee on Nutrition. The role of the pediatrician in primary prevention of obesity. Pediatrics. 2015; 136(1): e275-292. PMid:26122812. http://dx.doi.org/10.1542/ped s. 2015-1558

[8] Lundahl A, Kidwell KM, Nelson TD. Parental underestimates of child weight: A meta-analysis. Pediatrics. 2014; 133(3): e689703. PMid:24488736. http://dx.doi.org/10.1542/peds. 20 13-2690

[9] Perrin EM, Skinner AC, Steiner MJ. Parental recall of doctor communication of weight status: National trends from 1999 through 2008. Archives of Pediatrics and Adolescent Medicine. 2012; 166(4): 317-322. PMid:22147758. http://dx.doi.org/10.1001/archp ediatrics.2011.1135

[10] Davies MA, Terhorst L, Nakonechny AJ, et al. The development and effectiveness of a health information website designed to improve parents' self-efficacy in managing risk for obesity in preschoolers. Journal for Specialists in Pediatric Nursing. 2014; 19(4): 316-330. PMid:25160030.

[11] Taveras EM, Marshall R, Kleinman KP, et al. Comparative effectiveness of childhood obesity interventions in pediatric primary care: A cluster-randomized clinical trial. JAMA Pediatrics. 2015; 169(6): 535-542. PMid:25895016. http://dx.doi.org/10.1001/jamap ediatrics.2015.0182

[12] Hingle MD, O'Connor TM, Dave JM, et al. Parental involvement in interventions to improve child dietary intake: A systematic review. 
Preventive Medicine. 2010; 51(2): 103-111. http://dx.doi.org $/ 10.1016 / j$. ypmed .2010 .04 .014

[13] Moore LC, Harris CV, Bradlyn AS. Exploring the relationship between parental concern and the management of childhood obesity. Maternal and Child Health Journal. 2012; 16(4): 902 908. PMid:21594667. http://dx.doi.org/10.1007/s10995-0 $11-0813-x$

[14] Malik VS, Pan A, Willett WC, et al. Sugar-sweetened beverages and weight gain in children and adults: A systematic review and meta-analysis. The American Journal of Clinical Nutrition. 2013; 98(4): 1084-1102. PMid:23966427. http://dx.doi.org/10.39 45/ajcn. 113.058362

[15] Han E, Powell LM. Consumption patterns of sugar-sweetened beverages in the United States. Journal of the Academy of Nutrition and Dietetics. 2013; 113(1): 43-53. PMid:23260723. http: //dx.doi.org/10.1016/j.jand.2012.09.016

[16] Taber DR, Chriqui JF, Vuillaume R, et al. The association between state bans on soda only and adolescent substitution with other sugarsweetened beverages: A cross-sectional study. International Journal of Behavioral Nutrition and Physical Activity. 2015; 12 Suppl 1: S7. PMid:26221969. http://dx.doi.org/10.1186/1479-586 8-12-S1-S7

[17] Patel AI, Ritchie L. Striving for meaningful policies to reduce sugarsweetened beverage intake among young children. Pediatrics. 2013; 132(3): 566-568. PMid:23918894. http://dx.doi.org/10.1542 /peds. 2013-1799

[18] Ward D. Is your child at risk of becoming overweight? USA Today. Available from: http://usatoday30.usatoday.com/news/200 3-07-21-kids-chart.htm

[19] He M, Evans A. Are parents aware that their children are overweight or obese? Do they care? Canadian Family Physician. 2007; 53(9): 1493-1499. PMid:17872878.

[20] De Ruyter JC, Olthof MR, Seidell JC, et al. A trial of sugarfree or sugar-sweetened beverages and body weight in children. The New England Journal of Medicine. 2012; 367(15): 13971406. PMid:22998340. http://dx.doi.org/10.1056/NEJMoa1 203034
[21] Shefferly A, Scharf RJ, DeBoer MD. Longitudinal evaluation of $100 \%$ fruit juice consumption on BMI status in 2-5-year-old children. Pediatric Obesity. 2015. http://dx.doi.org/10.1111/ijpo.12 048

[22] Govindan M, Gurm R, Mohan S, et al. Gender differences in physiologic markers and health behaviors associated with childhood obesity. Pediatrics. 2013; 132(3): 468-474. PMid:23940242. http://dx.doi.org/10.1542/peds.2012-2994

[23] Hearst MO, Sherwood NE, Klein EG, et al. Parental perceptions of their adolescent's weight status: The ECHO study. American Journal of Health Behavior. 2011; 35(2): 248-255. PMid:21204687.

[24] Xie X, Wu H, Lee T, et al. Gender differences in home environments related to childhood obesity in Nanchang, China. Childhood Obesity. 2014; 10(5): 416-423. PMid:25302442. http://dx.doi.org/10. 1089/chi.2013.0164

[25] Hill C, Saxton J, Webber L, et al. The relative reinforcing value of food predicts weight gain in a longitudinal study of 7-10-y-old children. The American Journal of Clinical Nutrition. 2009; 90(2): 276-281. PMid:19535428. http://dx.doi .org/10.3945/ajcn . 2009. 27479

[26] Berlin KS, Kamody RC, Thurston IB, et al. Physical activity, sedentary behaviors, and nutritional risk profiles and relations to body mass index, obesity, and overweight in eighth grade. Behavioral Medicine. 2015. http://dx. doi .org/10.1080/08964289. 2015.1039956

[27] Cloutier MM, Wiley J, Huedo-Medina T, et al. Outcomes from a pediatric primary care weight management program: Steps to growing up healthy. Journal of Pediatrics. 2015; 167(2): 372377. PMid:26073106. http://dx.doi.org/10.1016/j.jpeds .2015 .05 .028

[28] Barlow SE, Expert Committee. Expert committee recommendations regarding the prevention, assessment, and treatment of child and adolescent overweight and obesity: Summary report. Pediatrics. 2007; 120 Suppl 4: S164-192. PMid:18055651. http://dx.doi .org/1 0.1542 /peds . 2007-2329C

[29] Cygan HR, Baldwin K, Chehab LG, et al. Six to success: improving primary care management of pediatric overweight and obesity. Journal of Pediatric Health Care. 2014; 28(5): 429-437. PMid:24725517. http://dx.doi.org/10.1016/j.pedhc. 2014.02.002 